\title{
CASE REPORT: \\ FIBROLAMELLAR CARCINOMA OF THE LIVER - A CASE REPORT FROM JAPAN AND A REVIEW OF THE LITERATURE
}

\author{
HITOSHI KOHNO, NAOFUMI NAGASUE*, HIROYUKI TANIURA, \\ TERUHISA NAKAMURA and SABRO NAGAOKA
}

Second Department of Surgery and Clinical Department of Pathology, Shimane Medical University, Izumo 693, Japan

The first Japanese case of fibrolamellar carcinoma (FLC) of the liver is described. The 17-year-old Japanese male affected died of the disease 25 months after palliative operation. The diagnosis of FLC had not been confirmed before autopsy. Pre-operative diagnosis of FLC is important to surgeons. Acccording to the literature, FLC is rare in Asia. The endemic discrepancy may suggest that the carcinogenic factors are different from those of general hepatocellular carcinoma.

KEY WORDS: Hepatocellular carcinoma, fibrolamellar carcinoma, hepatic artery ligation.

\section{INTRODUCTION}

Fibrolamellar carcinoma (FLC) of the liver has been widely recognized as a subtype of hepatocellular carcinoma (HCC) since $1980^{1,2}$. We herein report on a Japanese teenager affected by FLC.

\section{CASE REPORT}

A 17-year-old Japanese male underwent a laparotomy under pre-operative diagnosis of choledocholithiasis at Shimane Medical University on 27 December 1980. The choledochotomy revealed yellow-greenish emboli in the bile ducts. The histologies of both the emboli and the biopsied lymphnodes indicated HCCs (Figure 1). But it was not suggested that this HCC was FLC at that moment. Serum level of alphafetoprotein was below $5 \mathrm{ng} / \mathrm{ml}$ and that of carcino-embryonic antigen below $2.5 \mathrm{ng} /$ $\mathrm{ml}$. The patient was negative for both hepatitis B surface antigen and antibody. The second laparotomy revealed the hepatoma $(8 \times 8 \times 8 \mathrm{~cm})$ at the right hepatic lobe. Although hepatic-arteries ligation and infusion chemotherapy (5.25 g of 5fluorouracil and $100 \mathrm{mg}$ of Doxorubicin) were performed, the patient died on 9 February 1983. It was realized at the postmortem examination that the HCC of this patient was a special subtype.

* Correspondence and reprint requests to: Dr N. Nagasue, Second Department of Surgery, Shimane Medical University, Izumo 693, Japan. 


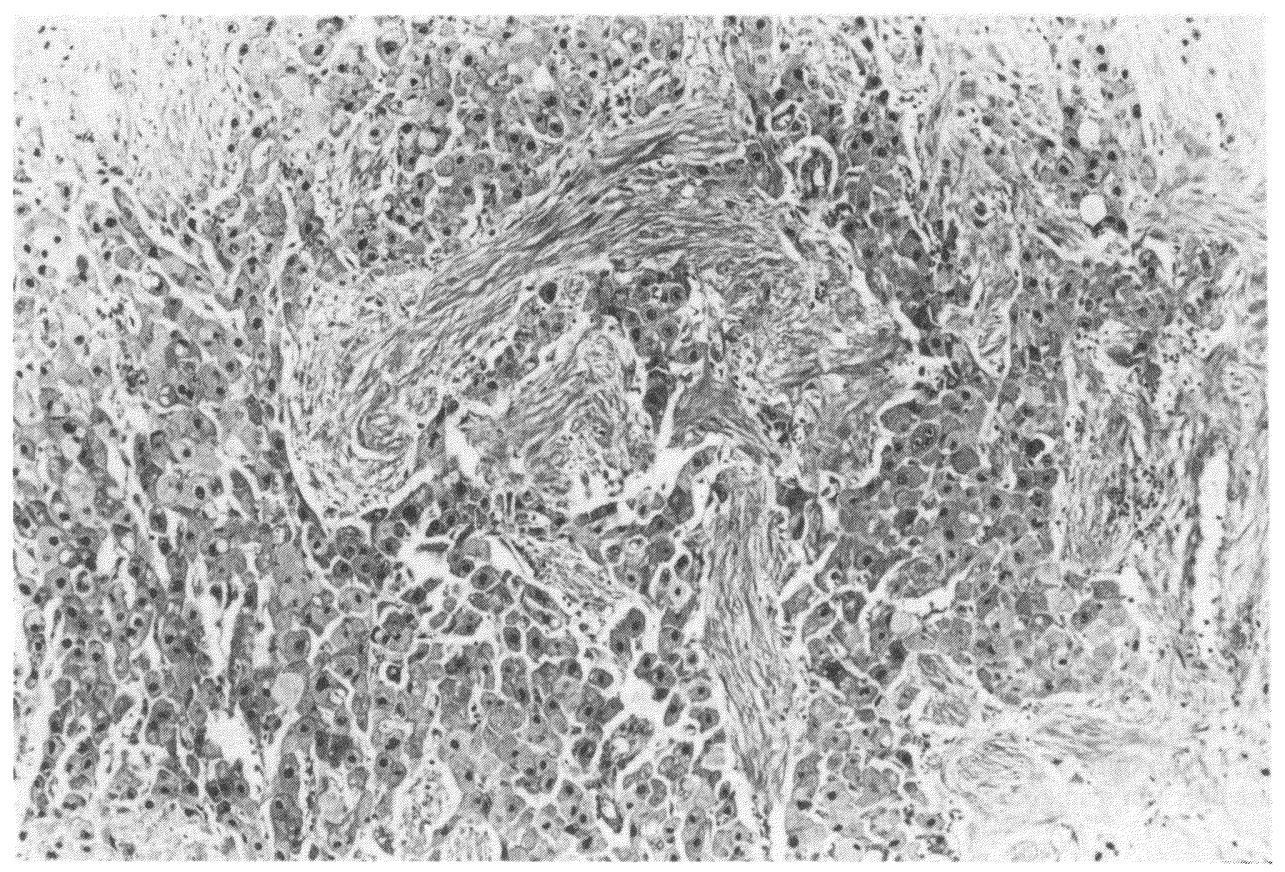

Figure 1 Histology of the tumor in the common hepatic duct shows lamellar fibrosis and polygonal malignant hepatocytes (H \& E 25).

\section{DISCUSSION}

In this case, the diagnosis of FLC was not made before autopsy. Although FLC has some diagnostic characteristics ${ }^{1-5}$, it seems difficult to make a definitive diagnosis before surgery in most patients ${ }^{6}$. Even so, such diagnosis may be necessary for surgeons to perform aggressive hepatic resection, since FLC can promise a relatively favorable prognosis after resection. This point has been stressed recently by Dawson $^{7}$. Furthermore, Calne ${ }^{8}$ and Starzl et al. ${ }^{9}$ have claimed that FLC is also a better candidate for liver transplantation.

Incidentally, the patient also had tumor invasion of bile ducts. It is worthwhile to note that FLC, like general HCC, develops intraductal tumor growth in some patients $^{10}$.

As far as we know from the literature, there have been 143 cases of FLC (Table 1) ${ }^{1-6,9-32}$. In Asia, where HCC is more frequent than in the West, there are only three cases, including the present case. The carcinogenic factors of FLC might be different from those of general HCC. Perhaps a world-wide survey is necessary to clarify this.

\section{Acknowledgements}

The authors thank Sir Roy Y. Calne for his encouragement and Prof. K. Okuda for confirming the histology. 
Table 1 Endemic aspects of fibrolamellar carcinoma in the literature ${ }^{a}$.

\begin{tabular}{llllll}
\hline Area & References & \multicolumn{4}{l}{ Race of patient } \\
\cline { 3 - 6 } & & White & Black & Yellow & Unknown \\
\hline North & $1,2,4,6,9^{\mathrm{b}}, 10,14-22$, & 61 & 6 & 1 & 53 \\
America & $23^{\mathrm{b}}, 24-28$ & & & & 19 \\
Europe & $3,5,11,29,30$ & - & - & - & 2 \\
Asia & 13 & - & - & $1^{\mathrm{c}}$ & 2 \\
\hline
\end{tabular}

a Three patients reported by Jagirdar et $a l^{12}$, three by Stromeyer et al $^{31}$ and nine by Goodman and Ishak ${ }^{32}$ are omitted to avoid overlap of patients.

${ }^{\mathrm{b}}$ Overlap of patients between these two articles is avoided by careful comparison.

${ }^{c}$ Our patient

\section{References}

1. Craig, J.R., Peters, R.L., Edmondson, H.A. and Omata, M. (1980) Fibrolamellar carcinoma of the liver: a tumor of adolescents and young adults with distinctive clinicopathologic features. Cancer, 46, 372-379

2. Berman, M.M., Libbey, N.P. and Foster, J.H. (1980) Hepatocellular carcinoma: polygonal cell type with fibrous stroma - an atypical variant with a favorable prognosis. Cancer, 46, 1448-1455

3. Paradinas, F.J., Melia, W.M., Wilkinson, M.L., Portmann, B., Johnson, P.J., Murray-Lyon, I.M. and Williams, R. (1982) High serum vitamin $B_{12}$ binding capacity as a marker of the fibrolamellar varianta of hepatocellular carcinoma. British Medical Journal, 285, 840-842

4. Friedman, A.C., Lichtenstein, J.E., Goodman, Z., Fishman, E.K., Siegelman, S.S. and Dachman, A.H. (1985) Fibrolamellar hepatocellular carcinoma. Radiology, 157, 583-587

5. Soreide, O., Czerniak, A., Bradpiece, H., Bloom, S. and Blumgart, L. (1986) Characteristics of fibrolamellar hepatocellular carcinoma: a study of nine cases and a review of the literature. The American Journal of Surgery, 151, 518-523

6. Suen, K.C., Magee, J.F., Halparin, L.S., Chan, N.H. and Greene, C.-A. (1985) Fine needle aspiration cytology of fibrolamellar hepatocellular carcinoma. Acta Cytologica, 29, 867-872

7. Dawson, J.L. (1986) An unusual hepatic cancer. British Journal of Surgery, 73, 331

8. Calne, R.Y. (1983) Liver Transplantation. London: Grune \& Straton

9. Starzl, T.E., Iwatsuki, S., Shaw, B.W., Nalesnik, M.A., Farhi, D.C. and Van Thiel, D.H. (1986) Treatment of fibrolamellar hepatoma with partial or total hepatectomy and transplantation of the liver. Surgery, Gynecology and Obstetrics, 162, 145-148

10. Albaugh, J.S., Keeffe, E.B. and Krippaehne, W.W. (1984) Recurrent obstructive jaundice caused by fibrolamellar hepatocellular carcinoma. Digestive Diseases and Sciences, 29, 762-767

11. Vecchio, F.M., Fabiano, A., Ghirlanda, G., Manna, R. and Massi, G. (1984) Fibrolamellar carcinoma of the liver: the malignant counterpart of focal nodular hyperplasia with oncocytic change. American Journal of Clinical Pathology, 81, 521-526

12. Jagirdar, J., Ishak, K.G., Colombo, M., Brambilla, C. and Paronetto, F. (1985) Fibronectin patterns in hepatocellular carcinoma and its clinical significance. Cancer, 56, 1643-1648

13. Hsu, H.-C., Sheu, J.-C., Lin, L.-H., Chen, D.-S., Lee, C.-S., Hwang, L.-Y. and Beasley, R.P. (1985) Prognostic histologic features of resected small hepatocellular carcinoma (HCC) in Taiwan: a comparison with resected large HCC. Cancer, 56, 672-680

14. Lack, E.E., Neave, C. and Vawter, G.F. (1983) Hepatocellular carcinoma: review of 32 cases in childhood and adolescence. Cancer, 52, 1510-1515

15. Wetzel, W.J., Costin, J.L. and Petrino, R.L. (1983) Fibrolamellar carcinoma: distinctive clinical and morphological variant of hepatoma. Southern Medical Journal, 76, 796-798

16. Francis, I.R., Agha, F.P., Thompson, N.W. and Keren, D.F. (1986) Fibrolamellar hepatocarcinoma: clinical, radiologic and pathologic features. Gastrointestinal Radiology, 11, 67-72

17. Govindarajan, S., Ashcavai, M. and Peters, R.L. (1981) Alpha-1-antitrypsin phenotypes in hepatocellular carcinoma. Hepatology, 1, 628-631 
18. Slavutin, L.J. and Diamond, N. (1981) Case report. Hepatocellular carcinoma with lamellar fibrosis: an important histological variant. Pathology, 13, 775-781

19. Albukerk, J. (1981) Hepatocellular carcinoma in young adults. New York State Journal of Medicine, 81, 1341-1344

20. Wong, L.K., Link, D. P., Frey, C.F., Ruebner, B.H., Tesluk, H. and Pimstone, N.R. (1982) Fibrolamellar hepatocarcinoma: radiology, management, and pathology. American Journal of Roentgenology, 139, 172-175

21. Chuoung, J.J.H., Livstone, E.M. and Barwick, K.W. (1982) The histologic and clinical indicators of prognosis in hepatoma. Journal of Clinical Gastroenterology, 4, 547-552

22. Lefkowitch, J.H., Muschel, R., Proice, J.B., Marboe, C. and Braunhat, S. (1983) Copper and copper-binding protein in fibrolamellar liver cell carcinoma. Cancer, 51, 97-100

23. Farhi, D.C., Shikes, R.H., Murari, P.J. and Silverberg, S.G. (1983) Hepatocellular carcinoma in young people. Cancer, 52, 1516-1525

24. An, T., Ghatak, N., Kastner, R., Kay, S. and Lee, H.M. (1983) Hyaline globules and intracellular lumina in a hepatocellular carcinoma. American Journal of Clinical Pathology, 79, 392-396

25. Giacomantonio, M., Ein, S.H., Mancer, K. and Stephens, C.A. (1984) Thirty years of experience with pediatric primary malignant liver tumours. Journal of Pediatric Surgery, 19, 523-526

26. Nagorney, D.M., Adson, M.A., Weiland, L.H., Knight, C.D., Smalley, S.R. and Zinsmeister, A.R. (1985) Fibrolamellar hepatoma. The American Journal of Surgery, 149, 113-119

27. Hromas, R.A., Srigley, J. and Murray, J.L. (1985) Clinical and pathological comparison of young adult women with hepatocellular carcinoma with and without exposure to oral contraceptives. The American Journal of Gastroenterology, 80, 479-485

28. Teitelbaum, D.H., Tuttle, S., Carey, L.C. and Clausen, K.P. (1985) Fibrolamellar carcinoma of the liver: review of three cases and the presentation of characteristic set of tumor markers defining this tumor. Annals of Surgery, 202, 36-41

29. Baithun, S.I. and Pollock, D.J. (1983) Oncocytic hepatocellular tumour. Histopathology. 7, 107-112

30. Sumithran, E. (1984) Fibrolamellar carcinoma of the liver. American Journal of Clinical Pathology, 82, 633-634

31. Stromeyer, F.W., Ishak, K.G., Gerber, M.A. and Mathew, T. (1980) Ground-glass cells in hepatocellular carcinoma. American Journal of Clinical Pathology, 74, 254-258

32. Goodman, Z.D. and Ishak, K.G. (1982) Hepatocellular carcinoma in women: probable lack of etiologic association with oral contraceptive steroids. Hepatology, 2, 440-444

Accepted by S. Bengmark on 20 April 1988. 


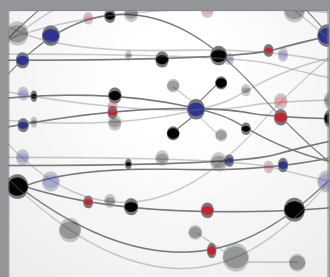

The Scientific World Journal
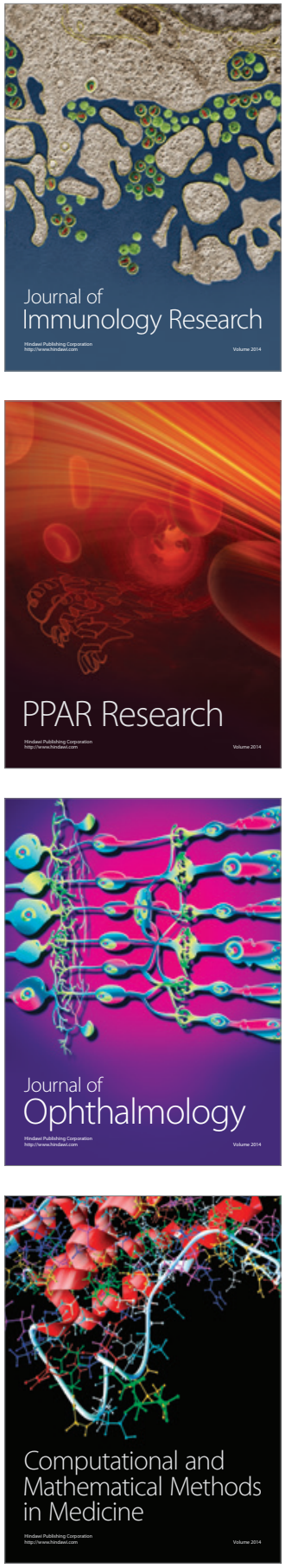

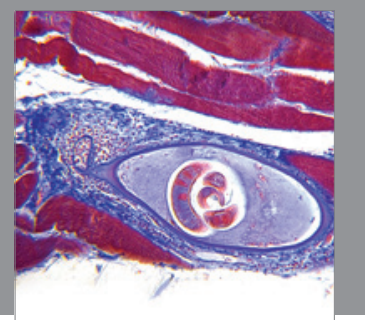

Gastroenterology

Research and Practice
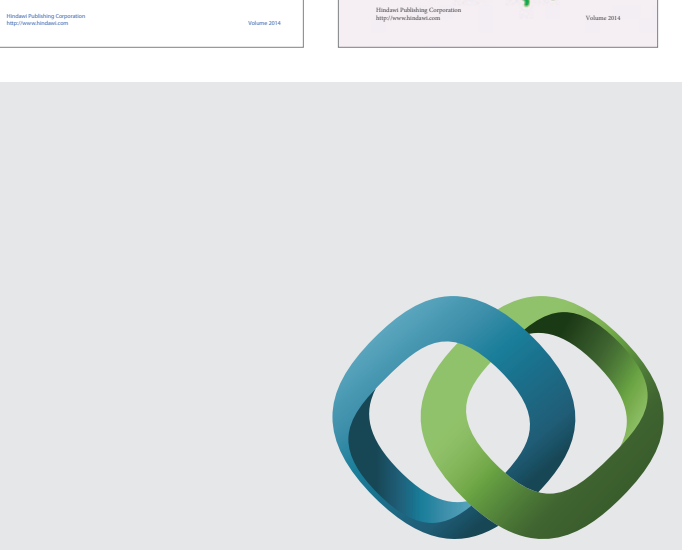

\section{Hindawi}

Submit your manuscripts at

http://www.hindawi.com
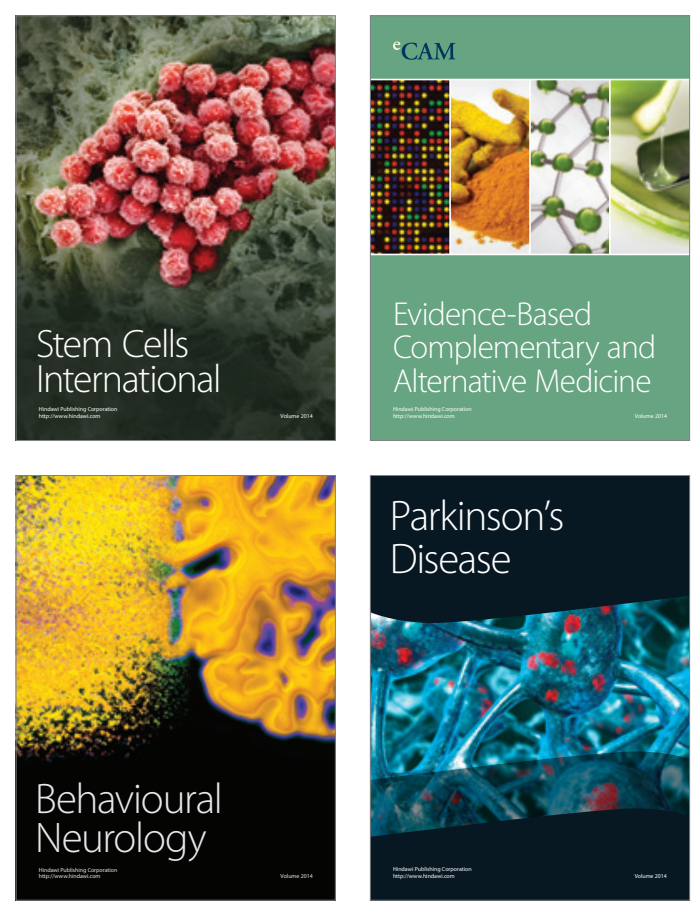

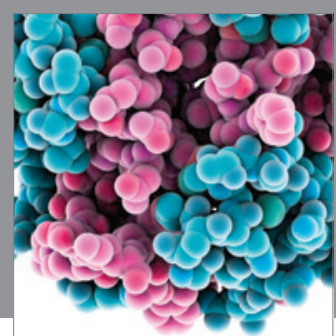

Journal of
Diabetes Research

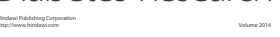

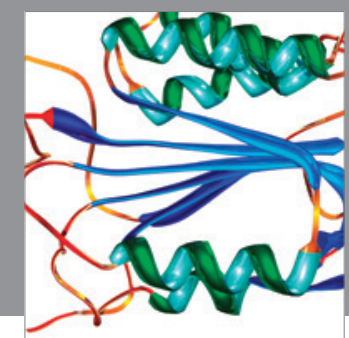

Disease Markers
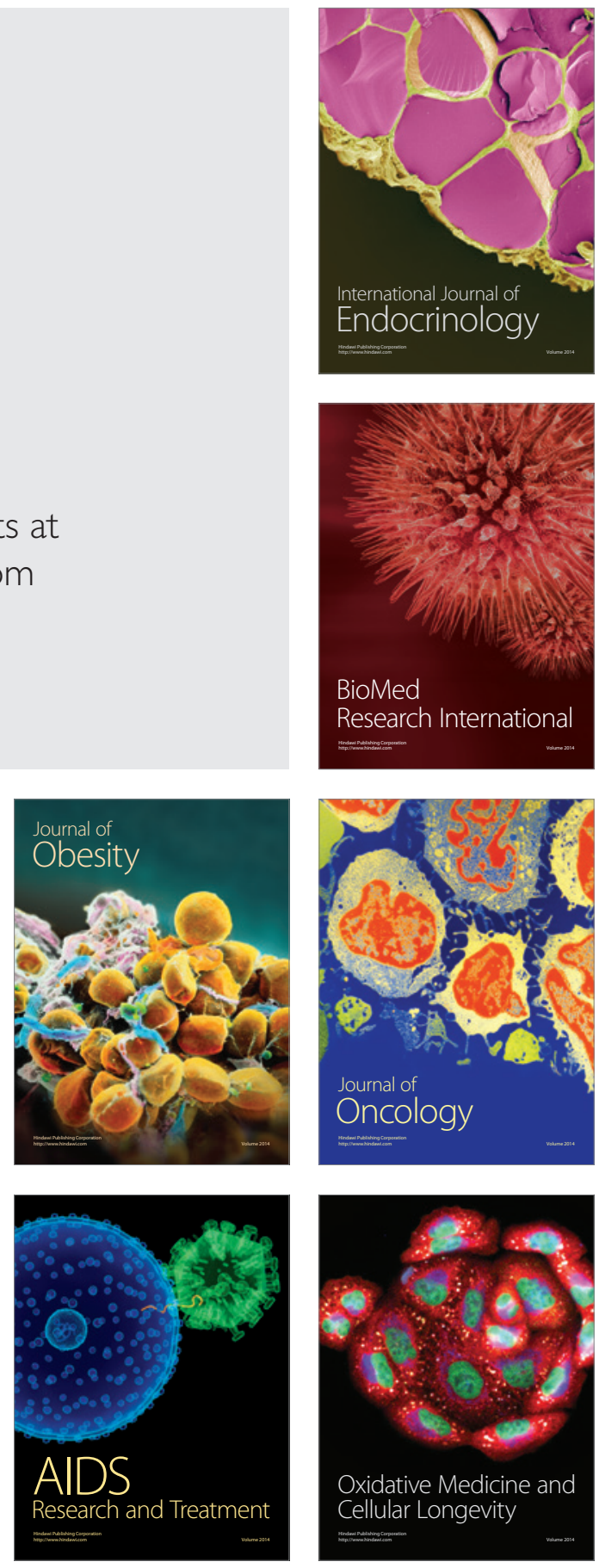